\title{
Emergência de plântulas de Erythrina velutina em diferentes posições e profundidades de semeadura
}

\author{
Emergency of the Erythrina velutina seedlings at different positions and sowing depths
}

\author{
Edson de Almeida Cardoso ${ }^{\mathrm{I}}$ Edna Ursulino Alves $^{\mathrm{I}{ }^{*}}$ Riselane de Lucena Alcântara Bruno ${ }^{\mathrm{II}}$ \\ Anarlete Ursulino Alves ${ }^{\text {III }}$ Adriana Ursulino Alves ${ }^{\text {IV }}$ Kelina Bernardo Silva ${ }^{\text {III }}$
}

\section{- NOTA -}

\section{RESUMO}

Com o objetivo de estudar a influência da posição e da profundidade de semeadura sobre a emergência de plântulas e o vigor de sementes de mulungu foram instalados testes de germinação em areia sob ambiente protegido. Os tratamentos, representados pela posição e pela profundidade de semeadura das sementes em relação ao substrato foram os seguintes: semente com o hilo voltado para baixo, para cima e para o lado nas profundidades de 1 a $5 \mathrm{~cm}$. Cada um dos tratamentos constou de quatro repetições de 25 sementes, avaliados pelo teste de emergência, vigor da primeira contagem, velocidade de emergência, comprimento e massa seca do hipocótilo e das raízes. Os resultados mostraram que, para o mulungu, a profundidade de semeadura dever ser entre 1 e $2 \mathrm{~cm}$ e, a melhor posição foi aquela em que as sementes ficaram com o hilo voltado para baixo.

Palavras-chave: mulungu, sementes florestais.

\section{ABSTRACT}

The aim of this research was to study the influence of the sowing depth and position upon seedling emergency and seed vigor of the coral tree, some germination tests were settled in sand, under protected environment. The treatments were represented by the position and depth of the seed sowings relative to the substratum, as follows: seed with the hilum turned down, upward and to the side at depths 1, 2, 3, 4 and $5 \mathrm{~cm}$. Each treatment consisted of four replicates with 25 seeds, and were evaluated by the following tests: emergence, first- counting vigor, emergency speed, length and dry mass of the hypocotyl and roots. According to the results for coral tree, the sowing depth should be between one and two centimeters, whereas the best position was the hilum turned down.

Key words: mulungu, forest seeds.

Erythrina velutina é uma planta de porte arbóreo bem comum nas caatingas, porém, sua área de dispersão inclui a várzea fluvio-marinha do Recife, de Minas Gerais, do Rio de Janeiro e de São Paulo e, mais ainda, das Antilhas, Norte da Venezuela, Norte da Colômbia, do Equador, das Ilhas Galápagos e do Peru. Suas aplicações vão desde o sombreamento de cacaueiros até a confecção de tamancos, caixotarias, brinquedos e jangadas (LIMA, 1989).

$O$ insucesso na germinação e o estabelecimento inicial da muda no campo está relacionado a fatores como o contato da semente com o solo, o deslocamento do ponto de semeadura, a semeadura muito profunda, o excesso ou escassez de umidade e as perdas de sementes e plântulas para insetos e aves (DOUGHERTY, 1990). O tipo de germinação destas sementes, epigeal, requer a realização de movimento rotatório por parte dos cotilédones dentro do solo, pois é possível que existam

'Curso de Agronomia, Centro de Ciências Agrárias (CCA), Universidade Federal da Paraíba (UFPB), Areia, PB, Brasil.

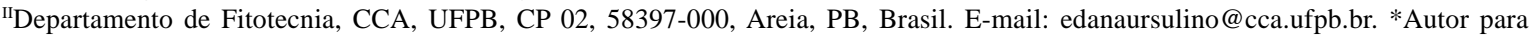
correspondência.

"IIPrograma de Pós-graduação em Agronomia, CCA, UFPB, Areia, PB, Brasil.

Iv Programa de Pós-graduação em Agronomia, Faculdade de Ciência Agrárias e Veterinária (FCAV), Universidade Estadual Paulista (UNESP), Jaboticabal, SP, Brasil. 
posições que facilitem ou que dificultem a emergência de plântulas (CARVALHO \& NAKAGAWA, 2000), como foi verificado em Euterpe espiritosantensis Fernandes (MARTINS et al., 1999), Oenocarpus mapora Karsten (NASCIMENTO et al., 2002) e Astrocaryum aculeatum Meyer (ELIAS et al., 2006).

A profundidade de semeadura ideal é aquela que garanta germinação homogênea das sementes e rápida emergência das plântulas, produzindo assim mudas vigorosas (SCHMIDT, 1974). Nesse sentido, CHAPMAN \& ALLAN (1989) recomendaram a profundidade de semeadura em 2,5 a 3,0 vezes a maior dimensão da semente. Em termos práticos, sementes pequenas devem ser espalhadas na superfície do substrato, as médias devem ser cobertas por uma camada de espessura aproximada de seu diâmetro e as sementes grandes, a uma profundidade de duas a três vezes o seu diâmetro (HARTMANN \& KESTER, 1983). Isso de ser feito porque o peso do material sobre a semente constitui um fator físico inibidor da emergência de plântulas e, quando muito superficial, as sementes recebem intenso calor do sol, não absorvendo umidade em quantidade adequada à germinação (CARNEIRO, 1995). As maiores porcentagens de plântulas emersas de Aspidosperma album ocorreu quando as sementes foram semeadas entre 0,5 e $1,0 \mathrm{~cm}$, enquanto para Sclerobium paniculatum Vog., Parkia multijuga Benth., Enterolobium timouva Mart. e Aniba sp. foi entre 0,5 e 2,0 (PEREIRA \& PEDROSO, 1982). De forma semelhante, SILVA et al. (1985) verificaram que houve decréscimo na emergência e na altura das plântulas de Tabebuia impetiginosa Mart. e Amburana cearensis L. com o aumento da profundidade de semeadura, enquanto FONSECA et al. (1994) sugeriram a profundidade próxima a zero centímetro para semeadura de sementes de Hancornia speciosa Gomes. O presente trabalho teve como objetivo estudar a influência da posição e da profundidade de semeadura sobre a emergência de plântulas de mulungu.

O trabalho foi conduzido em casa de vegetação, em Areia, Paraíba, com sementes de Erythrina velutina Willd., coletadas embaixo de 10 árvores matrizes no mesmo município. As sementes foram semeadas em bandejas plásticas perfuradas em substrato areia lavada e previamente esterilizada em autoclave, sendo que as profundidades de semeadura variaram de um a cinco centímetros com as sementes posicionadas com o hilo para o lado, para cima e para baixo, cada bandeja constou de quatro repetições de 25 sementes mantidas em condições normais de temperatura, fotoperíodo e umidade relativa do ar.

Foram avaliados os seguintes parâmetros: a emergência do número de plântulas emersas do $3^{30}$ ao
11ํ dia após a semeadura, a primeira contagem de emergência, que correspondeu à porcentagem acumulada de plântulas normais até $6^{\circ}$ dia após o início do teste, e o índice de velocidade de emergência (IVE) por meio de contagens diárias das plântulas normais durante 11 dias, e, o índice calculado conforme MAGUIRE (1962). Também foram avaliados o comprimento e massa seca de plântulas, sendo que aos onze dias após a semeadura as plântulas normais foram medidas com régua graduada em centímetros, em seguida postas para secar em estufa a $65^{\circ} \mathrm{C}$ por 48 horas e pesadas em balança analítica com precisão de $0,001 \mathrm{~g}$.

O delineamento experimental foi inteiramente ao acaso, com os tratamentos distribuídos em esquema fatorial 5 x 3 (profundidades e posições de semeadura), em quatro repetições. Pelo fato terem sido aplicados os testes de homogeneidade e normalidade e de não haver necessidade de transformação, os dados foram submetidos à análise da variância, utilizando-se o teste F e também a análise de regressão polinomial a 5\% de probabilidade de erro.

As sementes semeadas com o hilo para baixo expressaram a emergência máxima (99\%) na profundidade de $1,82 \mathrm{~cm}$, aquelas cujo hilo ficou direcionado para cima apresentaram o maior porcentual de emergência (63\%) na profundidade de 1,47cm, enquanto que na profundidade $2,04 \mathrm{~cm}$ verificou-se a maior porcentagem de emergência (89\%) para as sementes com o hilo para o lado (Figura 1A). Com exceção da posição com o hilo apontando para baixo, as demais foram prejudiciais à emergência das plântulas. Os resultados obtidos concordam com as observações de NAPIER (1985), o qual enfatizou que semeaduras profundas dificultam a emergência das plântulas e PASSOS \& FERREIRA (1991) ao acrescentar que a profundidade ideal de semeadura é a que garante germinação homogênea, rápida emergência das plântulas e produção de mudas vigorosas.

A porcentagem de emergência de plântulas por ocasião da primeira contagem decresceu com o aumento da profundidade de semeadura, independentemente da posição em que foram semeadas. No entanto, as sementes semeadas com hilo para baixo demonstraram maior vigor (Figura 1B), provavelmente pelo fato de não haver necessidade de movimentos da radícula para se fixar no substrato, uma vez que a mesma emerge próxima ao hilo.

Quanto ao índice de velocidade de emergência, verificou-se que o mesmo reduziu linearmente com as profundidades de semeadura, quando as sementes foram semeadas com o hilo voltado para baixo e para cima, enquanto nas sementes semeadas com hilo voltado para o lado verificou-se a 


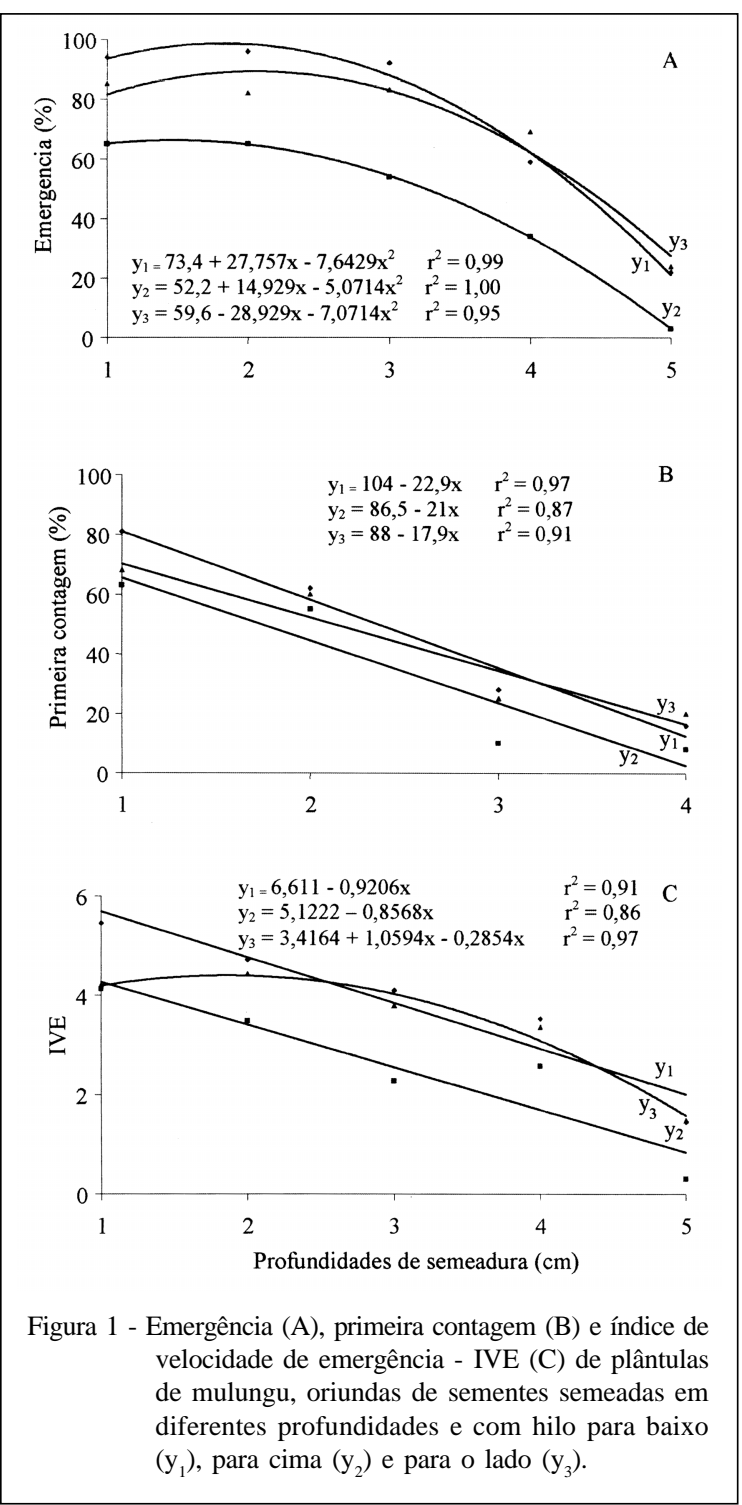

maior velocidade de emergência de plântulas $(4,40)$ na profundidade 1,86cm (Figura 1C). Provavelmente, isso ocorreu em virtude de nas maiores profundidades existir maior concentração de $\mathrm{CO}_{2}$, acarretando, assim, efeito fitotóxico, afetando tanto a porcentagem quanto a velocidade de emergência. Por outro lado, acreditase que a redução da velocidade de emergência está associada com as flutuações das temperaturas diurnas e noturnas, que favorecem, principalmente, as sementes plantadas nas menores profundidades.

As plântulas oriundas de sementes semeadas com o hilo para baixo tinham maior comprimento $(21,25 \mathrm{~cm})$ na profundidade de $2,14 \mathrm{~cm}$, aquelas cujo hilo ficou voltado para cima expressaram maior comprimento $(20,70 \mathrm{~cm})$ na profundidade de $2,36 \mathrm{~cm}$. Na profundidade de $2,36 \mathrm{~cm}$, verificou-se o maior comprimento da raiz primária $(20,25 \mathrm{~cm})$ das plântulas originadas de sementes com o hilo para o lado (Figura 2A). Provavelmente, houve um gasto maior de energia durante a fase de emergência, o que prejudicou o desenvolvimento normal das plântulas oriundas de sementes submetidas às maiores profundidades. Sementes de Pinus taeda L., nas profundidades de três e cinco centímetros, também originaram plântulas mais debilitadas, com menor capacidade de sobrevivência (BRUM et al., 1999).

Quanto ao conteúdo de massa seca das plântulas, verificou-se que aquelas oriundas de sementes com o hilo para baixo apresentaram maior conteúdo de massa seca da parte aérea $(0,236 \mathrm{~g})$ na profundidade de $0,50 \mathrm{~cm}$, aquelas cujo hilo ficou direcionado para cima expressaram maior conteúdo de massa seca da parte aérea $(0,200 \mathrm{~g})$ na profundidade de $1,67 \mathrm{~cm}$. Na profundidade $1,24 \mathrm{~cm}$, foi verificado o maior conteúdo de massa seca da parte aérea $(0,198)$ das plântulas originadas de sementes com hilo para o lado (Figura 2B). SILVA et al. (2006) também obtiveram plântulas mais vigorosas de Oenocarpus minor Mart. quando originadas de sementes em profundidades menores do que $2 \mathrm{~cm}$.

As profundidades de semeadura entre $1 \mathrm{e}$ $2 \mathrm{~cm}$ não diferiram para testes de germinação de sementes e emergência de plântulas de Erytrhina

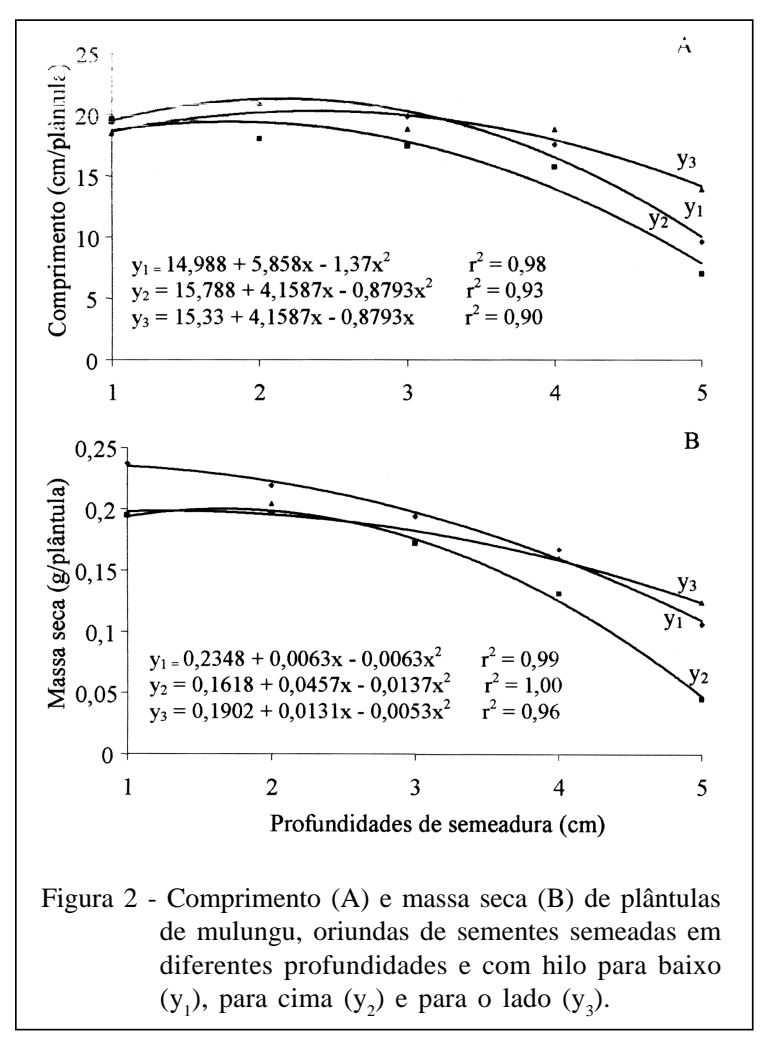

Ciência Rural, v.38, n.9, dez, 2008. 
velutina em casa-de-vegetação e a melhor posição foi aquela com o hilo voltado para baixo.

\section{REFERÊNCIAS}

BRUM, E.S. et al. Emergência e sobrevivência de Pinus taeda L. em semeadura direta a diferentes profundidades. Revista Brasileira de Agrociência, Pelotas, v.5, n.3, p.190-194, 1999.

CARnEIRO, J.G.A. Produção e controle de qualidade de mudas florestais. Curitiba: UFPR/FUPEF, 1995. 451p.

CARVALHO, N.M.; NAKAGAWA, J. Sementes: ciência, tecnologia e produção. 4.ed. Jaboticabal: FUNEP, 2000. 429p.

CHAPMAN, G.W.; ALLAN, T.G. Técnicas de estabelecimento de plantaciones forestales. Roma: FAO - Organizacion Das Naciones Unidas Para La Agricultura y La Alimentación, 1989. 206p.

DOUGHERTY, P.M. A field investigation of the factors which control germination and establishment of loblolly pine seeds. Georgia: Forestry Commission, 7. 1990. 5p.

ELIAS, M.E.A. et al. Emergência de plântulas de tucumã (Astrocaryum aculeatum) em função da posição de semeadura. Acta Amazonica, Manaus, v.36, n.3, p.385-388, 2006.

FONSECA, C.E.L. et al. Influência da profundidade de semeadura e da luminosidade na germinação de sementes de mangaba (Hancornia speciosa Gom.). Pesquisa Agropecuária Brasileira, Brasília, v.29, n.4, p.661-666, 1994.

HARTMANN, H.T.; KESTER, D.E. Plant propagation: principles and practices. New York: Englewood Clipps, Prentice-Hall, 1983. 727p.

LIMA. Plantas das caatingas. Rio de Janeiro: Academia Brasileira de Ciências, 1989. 245p.
MAGUIRE, J.D. Speed of germination aid in selection and evaluation for seedling emergence and vigor. Crop Science, Madison, v.2, n.2, p.176-177, 1962.

MARTINS, C.C. et al. Efeito da posição da semente no substrato e no crescimento inicial das plântulas de palmitovermelho (Euterpe espiritosantensis Fernandes - Palmae). Revista Brasileira de Sementes, Brasília, v.21, n.1, p.164173, 1999.

NAPIER, I.A. Tecnicas de viveros florestales con referencia especial a centroamerica. Costa Rica: Signa Tepec, Espemacifor, 1985. 274p.

NASCIMENTO, W.M.O. et al. Influência da posição de semeadura na germinação, vigor e crescimento inicial de plântulas de bacabinha (Oenocarpus mapora Karsten Arecaceae). Revista Brasileira de Sementes, Londrina, v.24, n.1, p.179-182, 2002.

PASSOS, M.A.A.; FERREIRA, R.L.C. Influência da cobertura de semeio na emergência e desenvolvimento inicial de algaroba. Revista Brasileira de Sementes, Brasília, v.13, n.2, p.51-153, 1991.

PEREIRA, A.P.; PEDROSO, L.M. Influência da profundidade de semeadura em algumas essências florestais da Amazônia. Silvicultura em São Paulo, São Paulo, v.16A, n.2, p.10921099, 1982

SCHMIDT, P.B. Sobre a profundidade ideal de semeadura do mogno (aguano) Swietenia macrophylla King. Brasil Florestal, Brasília, v.5, n.17, p.42-47, 1974.

SILVA, B.M.S. et al. Germinação de sementes e emergência de plântulas de Oenocarpus minor Mart. (Arecaceae). Revista Brasileira de Fruticultura, Jaboticabal, v.28, n.2, p.289292, 2006.

SILVA, H.D. et al. Efeito da profundidade de semeadura na formação de mudas de pau-d'arco e imburana-decheiro. Petrolina - PE: CPATSA - EMBRAPA, 1985. 16p. ( Boletim de Pesquisa, 24). 